\title{
Crystal Phases and Chemical Stabilities of YSi 2 Powders Fabricated from Low and High Purity Si and Y Powders
}

\author{
Ren Matsushima, Mikito Kitayama \\ Department of Life, Environment, and Applied Chemistry, Fukuoka Institute of Technology, Fukuoka, Japan \\ Email: kitayama@fit.ac.jp
}

How to cite this paper: Matsushima, R. and Kitayama, M. (2022) Crystal Phases and Chemical Stabilities of $\mathrm{YSi}_{2}$ Powders Fabricated from Low and High Purity Si and Y Powders. Journal of Materials Science and Chemical Engineering, 10, 18-28. https://doi.org/10.4236/msce.2022.102002

Received: January 17, 2022

Accepted: February 22, 2022

Published: February 25, 2022

Copyright ( 2022 by author(s) and Scientific Research Publishing Inc. This work is licensed under the Creative Commons Attribution International License (CC BY 4.0). http://creativecommons.org/licenses/by/4.0/

\begin{abstract}
$\mathrm{Y}$-Si compounds with the composition of $\mathrm{Y}: \mathrm{Si}=1: 2$ were fabricated using Yttrium and Silicon raw powders with low and high purity in various atmospheres and temperatures. Although the latest $\mathrm{Y}$-Si phase diagram shows that the $\alpha$ - and $\beta-\mathrm{YSi}_{2}$ phases are the stable phases for the stoichiometric composition of $\mathrm{Y}: \mathrm{Si}=1: 2$, the current experimental results suggest that the high temperature phase with the hexagonal structure, $\beta-\mathrm{Y}_{3} \mathrm{Si}_{5}$, would be the stable phase for this composition, and that the high temperature phase with the orthorhombic structure, $\beta$-YSi ${ }_{2}$, would be the meta-stable phase with high oxygen impurity content. It was demonstrated that $\mathrm{YSi}_{2}$ powders possess much superior chemical stability than Yttrium metal. It was found that the best dispersing solvent was 2-propanol for $\mathrm{YSi}_{2}$ powder.
\end{abstract}

\section{Keywords}

$\mathrm{YSi}_{2}$, Yttrium Silicide, Crystal Phase, Chemical Stability, Oxygen Impurity

\section{Introduction}

The latest Y-Si phase diagram shown in Figure 1 [1] demonstrated four congruently melting compounds, $\mathrm{Y}_{5} \mathrm{Si}_{3}$ (melting point (m.p.) $1844^{\circ} \mathrm{C}$ ), $\mathrm{Y}_{5} \mathrm{Si}_{4}$ (m.p. $1860^{\circ} \mathrm{C}$ ), $\mathrm{YSi}\left(\mathrm{m} . \mathrm{p} .1878^{\circ} \mathrm{C}\right.$ ) and $\mathrm{Y}_{3} \mathrm{Si}_{5}$ (m.p. $1612^{\circ} \mathrm{C}$ ). In addition to these phases, there is one peritectically melting compound, $\mathrm{YSi}_{2}\left(\mathrm{~m} . \mathrm{p} .1508^{\circ} \mathrm{C}\right.$ ). The phase diagram [1] was calculated based on thermodynamic data [2], however the polymorphic transformations in $\mathrm{Y}_{3} \mathrm{Si}_{5}$ and $\mathrm{YSi}_{2}$ were not based on thermodynamic calculation but on the thermodynamic assessments [2] [3]. Among, these five compounds, the existence of the $\mathrm{YSi}_{2}$ phase had been controversial. A detailed investigation of phase equilibria and crystal structures of the compounds by 
methods of thermal, metallographic, $\mathrm{x}$-ray phase analyses and by hardness measurement was carried out [4]. The existence of the compounds $\mathrm{Y}_{5} \mathrm{Si}_{3}, \mathrm{Y}_{5} \mathrm{Si}_{4}, \mathrm{YSi}$, and $\mathrm{Y}_{3} \mathrm{Si}_{5}$ was established, but the formation of $\mathrm{YSi}_{2}$ was not confirmed as a stable phase. Thus, the former version of the Y-Si phase diagram [5] did not include the $\mathrm{YSi}_{2}$ phase. Later, the method of measuring the electromotive forces $(e m f)$ of the concentration galvanic elements determined the thermodynamic functions of the formation of the Y-Si compounds, and all five compounds were confirmed [6]. The standard enthalpies of formation for some $4 \mathrm{~d}$ transition metal silicides have been measured by high temperature direct synthesis calorimetry at $1473 \mathrm{~K}$, and the $\mathrm{YSi}_{2}$ was also confirmed as a stable phase [7].

Early works regarding rare-earth disilicides [8] [9] [10] revealed that $\mathrm{YSi}_{2}$ was dimorphic, crystallizing in the hexagonal system $\left(\mathrm{AlB}_{2}\right.$ type $)$ at low temperatures $\left(\beta-\mathrm{YSi}_{2}\right)$ and in the orthorhombic system (distorted form of the tetragonal $\mathrm{ThSi}_{2}$ structure) at higher temperatures $\left(\alpha-\mathrm{YSi}_{2}\right)$, which was reported that $\alpha$-YSi $i_{2}$ transformed to $\beta-\mathrm{YSi}_{2}$ at $450^{\circ} \mathrm{C}$ [9]. However, the latest Y-Si phase diagram [1] shows the opposite designations for dimorphic $\mathrm{YSi}_{2}$, the low and high temperature phases are $\alpha-\mathrm{YSi}_{2}$ with the hexagonal crystal structure (space group: $P 6 / \mathrm{mmm}, \mathrm{AlB}_{2}$ type) and $\beta-\mathrm{YSi}_{2}$ with the orthorhombic crystal structure (space group: $I 4_{1} /$ amd, distorted form of the tetragonal $\mathrm{ThSi}_{2}$ type), respectively, and the phase transformation occurs at much higher temperature, $1242^{\circ} \mathrm{C}$. This apparent contradiction would be due to the oxygen impurity derived from the raw

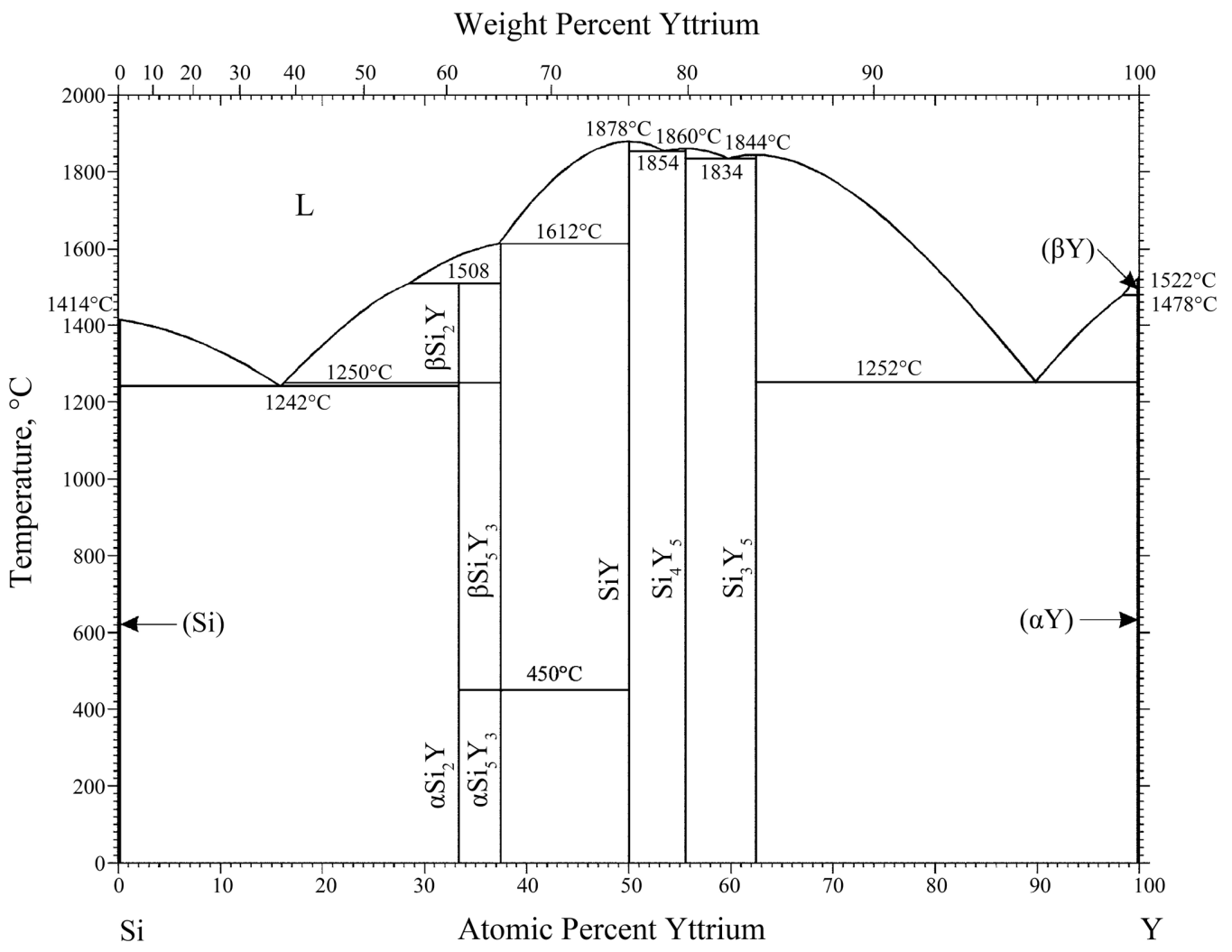

Figure 1. Y-Si phase diagram shown with a copy permission of Ref. [1]. 
metal powders. Even though the stoichiometric mixture of $\mathrm{Y}: \mathrm{Si}=1: 2$, was used for preparing the compound, partial oxidation of raw metal powders, especially that of Yttrium metal with much higher chemical activity, would make Yttrium metal to the mixture of $\mathrm{Y}$ and $\mathrm{Y}_{2} \mathrm{O}_{3}$. Also, high purity Si metals, even if the semi-conductor grades were used, always contain oxygen impurity, since only metal impurities would be accounted for those applications. Thus, the vaporization of $\mathrm{SiO}$ at high temperature according to the chemical reaction (1) and/or during the silicothermic reduction of $\mathrm{Y}_{2} \mathrm{O}_{3}(2)$ would reduce the amount of $\mathrm{Si}$ [8].

$$
\begin{gathered}
\mathrm{Si}+\mathrm{SiO}_{2} \rightarrow 2 \mathrm{SiO} \\
\mathrm{Si}+\mathrm{Y}_{2} \mathrm{O}_{3} \rightarrow 2 \mathrm{Y}+3 \mathrm{SiO}
\end{gathered}
$$

These reactions would result in the formation of $\mathrm{Y}_{3} \mathrm{Si}_{5}$ instead of $\mathrm{YSi}_{2}$ from the stoichiometric mixture of $\mathrm{Y}: \mathrm{Si}=1: 2$. Actually, the low temperature phase of $\mathrm{Y}_{3} \mathrm{Si}_{5}$ is the $\alpha-Y_{3} \mathrm{Si}_{5}$ with the orthorhombic crystal structure (space group: $I 4_{1} /$ amd, distorted form of the tetragonal $\mathrm{ThSi}_{2}$ type), which is identical to that of the low temperatures form of $\beta$-YSi ${ }_{2}$ reported in the early works [8] [9] [10]. This speculation would be further supported by the fact that the phase transformation from $\alpha$ - to $\beta$-Y $\mathrm{Y}_{3} \mathrm{Si}_{5}$ occurred at about $450^{\circ} \mathrm{C}$, which was close to that of $\beta$ - to $\alpha$ - $\mathrm{YSi}_{2}$ reported in the earlier works [8] [9] [10]. It was reported that euiatomic phase YSi appeared to be little affected by oxygen, however, the presence of oxygen in high temperature preparations involving $\mathrm{Y}_{3} \mathrm{Si}_{5}$ could stabilize the hexagonal structure towards greater silicon deficiency and a $\mathrm{Y}: \mathrm{Si}$ composition of $\mathrm{Y}_{2} \mathrm{Si}_{3}$ whilst low temperature material of " $\mathrm{Y}_{2} \mathrm{Si}_{3} \mathrm{O}_{\mathrm{x}}$ " composition had an unstable orthorhombic structure [4]. Thus, the presence of oxygen during preparing the Y-Si compounds could significantly influence the phase identification results of this system.

It is well known that transition metal silicides possess good potential for use as structural materials at high temperature. However, high temperature oxidation behaviors about active metal silicides such as Yttrium Silicides have been rarely known. It was reported that undoped $\mathrm{Y}_{5} \mathrm{Si}_{3}$ showed poor oxidation resistance above $700^{\circ} \mathrm{C}$ due to mechanical failure under stresses produced by growth of the oxidation product [11]. Because $\mathrm{YSi}_{2}$ nanoparticles incorporated SiGe exhibited excellent thermoelectric (TE) properties, the bulk $\mathrm{YSi}_{2}$ was fabricated and the TE properties were investigated recently [12]. However, no physical and/or chemical properties have been reported for $\mathrm{YSi}_{2}$ powder. The purpose of this work is to investigate the physical and chemical properties of $\mathrm{YSi}_{2}$ powders fabricated by various methods paying special attention to their oxygen impurities.

\section{Experimental}

\subsection{Synthesis of Low Purity $\mathrm{YSi}_{2}$ Powders}

Yttrium metal powder (purity > 99.9\%, under 20 mesh; RARE METALLIC Co., 
Ltd.) supplied as paraffin slurry was separated by vacuum filtration and washed several times with hexane. Silicon powder (purity $>98.0 \%$, under 100 mesh; Oxygen content $=1.03 \mathrm{wt} \%$; Fuji film Wako Pure Chemical Corp.) was pulverized by using a rotary ball mill at $118 \mathrm{rpm}$ for $8 \mathrm{hrs}$ using $5 \mathrm{mm \phi} \mathrm{Si}_{3} \mathrm{~N}_{4}$ grinding media to give the Si powder having mean particle size of $8.3 \mu \mathrm{m}$ and oxygen content $=$ $1.17 \mathrm{wt} \%$. These powders were mixed with a composition of $\mathrm{Y}: \mathrm{Si}=1: 2$ in molar ratios, and uniaxially pressed at $30 \mathrm{MPa}$ in a $15 \mathrm{~mm}$ diameter stainless-steel die. The powder compact was placed in a quartz tube (inner diameter $=10 \mathrm{~mm}$ and length $=10 \mathrm{~cm}$ ), which was evacuated using a rotary pump, and then was sealed using a $\mathrm{H}_{2}-\mathrm{O}_{2}$ gas burner. The quartz tube was heat treated at $1100^{\circ} \mathrm{C}$ for $5 \mathrm{hr}$ using a muffle furnace (Model MPC10; ADVANTEC Co., Ltd.) using the heating rate of $10^{\circ} \mathrm{C} / \mathrm{min}$.

The same powder compact was placed in a high purity $\mathrm{BN}$ crucible (N-1 grade; DENKA Company Ltd.), which was heat treated in a graphite susceptor at $1090^{\circ} \mathrm{C}$ for $5 \mathrm{hrs}$ or $1500^{\circ} \mathrm{C}$ for $1 \mathrm{hr}$ using a vacuum furnace with a graphite heating element (Model FVPHP-R-3: FUJIDENPA KOGYO Co., Ltd.). Heating and cooling rates were both $10^{\circ} \mathrm{C} / \mathrm{min}$.

\subsection{Synthesis of High Purity $\mathrm{YSi}_{2}$ Powders}

A Yttrium metal ingot (purity > 99.9\%, 7 - $10 \mathrm{~mm}$; RARE METALLIC Co., Ltd.) was surrounded by Si powder (Purity $>99.99 \%$, Oxygen content $=0.081 \mathrm{wt} \%$, $300 \mu \mathrm{m}$ pass; KOJUNDO CHEMICAL LABORATORY Co., Ltd.) using the molar ratio of $\mathrm{Y}: \mathrm{Si}=1: 2$ in a high purity $\mathrm{BN}$ crucible ( $\mathrm{N}-1$ grade; DENKA Company Ltd.), which was heat treated in a graphite susceptor at $1600^{\circ} \mathrm{C}$ for $30 \mathrm{~min}$ under $\mathrm{Ar}$ atmosphere of $0.1 \mathrm{MPa}$ using a furnace with a graphite heating element. Heating and cooling rates were both $10^{\circ} \mathrm{C} / \mathrm{min}$.

\subsection{Chemical Stability Tests of $\mathrm{YSi}_{2}$ Powders}

A small amount of pulverized $\mathrm{YSi}_{2}$ powder was immersed to various solvents including purified water, methanol (>99.8\%), ethanol (>99.5\%), propanol (>99.7\%), butanol ( $>99.5 \%)$, benzene ( $>99.5 \%), n$-hexane $(>96.0 \%)$, or acetonitrile $(>99.5 \%)$ in a test tube, and was settled for $24 \mathrm{hrs}$ at room temperature under the atmospheric condition observing every hour whether the formation of bubbles or white precipitates occurred or not.

Low purity $\mathrm{YSi}_{2}$ powder synthesized at $1500^{\circ} \mathrm{C}$ for $1 \mathrm{hr}$ and high purity $\mathrm{YSi}_{2}$ powder synthesized at $1600^{\circ} \mathrm{C}$ for $30 \mathrm{~min}$ were ground for $12 \mathrm{hrs}$ by using a rotary ball mill at $120 \mathrm{rpm}$ in various solvents including 2-propanol, $n$-hexane, or acetonitrile using $5 \mathrm{~mm} \phi \mathrm{Si}_{3} \mathrm{~N}_{4}$ grinding media at room temperature under the atmospheric condition. After milling, each solvent was removed using a rotary evaporator, dried in an oven at $120^{\circ} \mathrm{C}$ for $6 \mathrm{hrs}$, and sieved by passing through a 60 mesh nylon sieve. The oxygen content of each powder was determined by the hot-gas extraction method (EMGA-920, HORIBA Ltd.) using $20 \mathrm{mg}$ powder sample encapsulated with $1.0 \mathrm{~g}$ pure iron in a Ni crucible. 


\section{Results and Discussion}

\subsection{Fabrication Conditions and XRD Identification Results of Y-Si Compounds}

Table 1 summarizes the fabrication conditions of $\mathrm{Y}$-Si compounds with $\mathrm{Y}: \mathrm{Si}=$ 1:2 composition indicating five powder samples as No. 1-5. Figure 2 shows the XRD patterns of powder samples No. 1-4. Since the XRD pattern of sample No. 5 was found to be identical to that of No. 4, Figure 2 lacks its XRD pattern. Table 2 summarizes the XRD identification results of $\mathrm{Y}$-Si compounds prepared in this work. Table 3 and Table 4 compare powder XRD peak data obtained in this work having 1) hexagonal and 2) orthorhombic, respectively, crystal structures with those of Powder Diffraction File (PDF) database registered by the International Centre for Diffraction Data (ICDD). As shown in Table 2, Y-Si compounds with hexagonal structure were identified as $\alpha-\mathrm{YSi}_{2}$ or $\beta-\mathrm{Y}_{3} \mathrm{Si}_{5}$, because both phases are indistinguishable with their XRD patterns as shown in Table 3.

It was reported that $\alpha-\mathrm{YSi}_{2}$ and $\beta-\mathrm{Y}_{3} \mathrm{Si}_{5}$ had the identical crystal structure, $\mathrm{P} 6 / \mathrm{mmm}$, and $\beta-\mathrm{Y}_{3} \mathrm{Si}_{5}$ had defect structure: $\mathrm{Si}$ atoms occupy $83 \%$ of the $2(\mathrm{~d})$ positions in the space group $\mathrm{P} 6 / \mathrm{mmm}$ [13]. Also, the orthorhombic phase was identified as $\beta-\mathrm{YSi}_{2}$, because it was reported that the low temperature phase $\alpha-\mathrm{Y}_{3} \mathrm{Si}_{5}$ (Ortho.) was stable below $450^{\circ} \mathrm{C}$ [9]. Apparently, only sample No.2 has the orthorhombic structure, and the other samples possess the hexagonal structure as shown in Table 3 and Table 4. Samples No. 1 and 2 were fabricated with low purity metal powders at virtually the same temperature around $1100^{\circ} \mathrm{C}$, at which the low temperature phase, $\alpha$-YSi ${ }_{2}$, should be stable according to the latest phase diagram [1]. However, sample No. 2 fabricated at $1090^{\circ} \mathrm{C}$ in a graphite furnace under vacuum condition (continuously evacuated using a rotary pomp) possesses the orthorhombic structure, the high temperature phase stable above $1250^{\circ} \mathrm{C}$. It would be noteworthy that sample No. 3 that was fabricated at $1500^{\circ} \mathrm{C}$ in the same conditions other than temperature as sample No. 2 possesses the hexagonal structure, the low temperature phase stable below $1250^{\circ} \mathrm{C}$. This apparent contradiction would be explained as follows; Samples No. 1-3 were fabricated using Yttrium powder, which should contain a significant amount of surface oxygen, although the oxygen content was not accounted for its purity, 99.9\% that accounted only for the total metal impurity. Because sample No.1 was fabricated in a sealed quartz tube (closed system), the vaporization of $\mathrm{SiO}$ according to Equation (1) would be suppressed. This speculation would be supported by the fact that weak peaks of $\mathrm{Y}_{2} \mathrm{O}_{3}$ are observed only in the sample No.1, which also shows middle intensities of Si peaks suggesting that Equation (1) be suppressed. However, when heat-treated under vacuum (open system), the amount of Si and $\mathrm{Y}_{2} \mathrm{O}_{3}$ would be reduced according to Equations (1) and (2), respectively, resulting the formation of unstable phase with orthorhombic structure [4] as observed for sample No. 2. When heat-treated at higher temperature, $1500^{\circ} \mathrm{C}$, this unstable $\mathrm{Y}_{2} \mathrm{Si}_{3} \mathrm{O}_{x}$ phase would decompose to the stable phases, $\beta-\mathrm{Y}_{3} \mathrm{Si}_{5}$ and $\mathrm{Y}_{2} \mathrm{SiO}_{5}$ and/or $\mathrm{Y}_{2} \mathrm{Si}_{2} \mathrm{O}_{7}$ as shown in Table 2. 


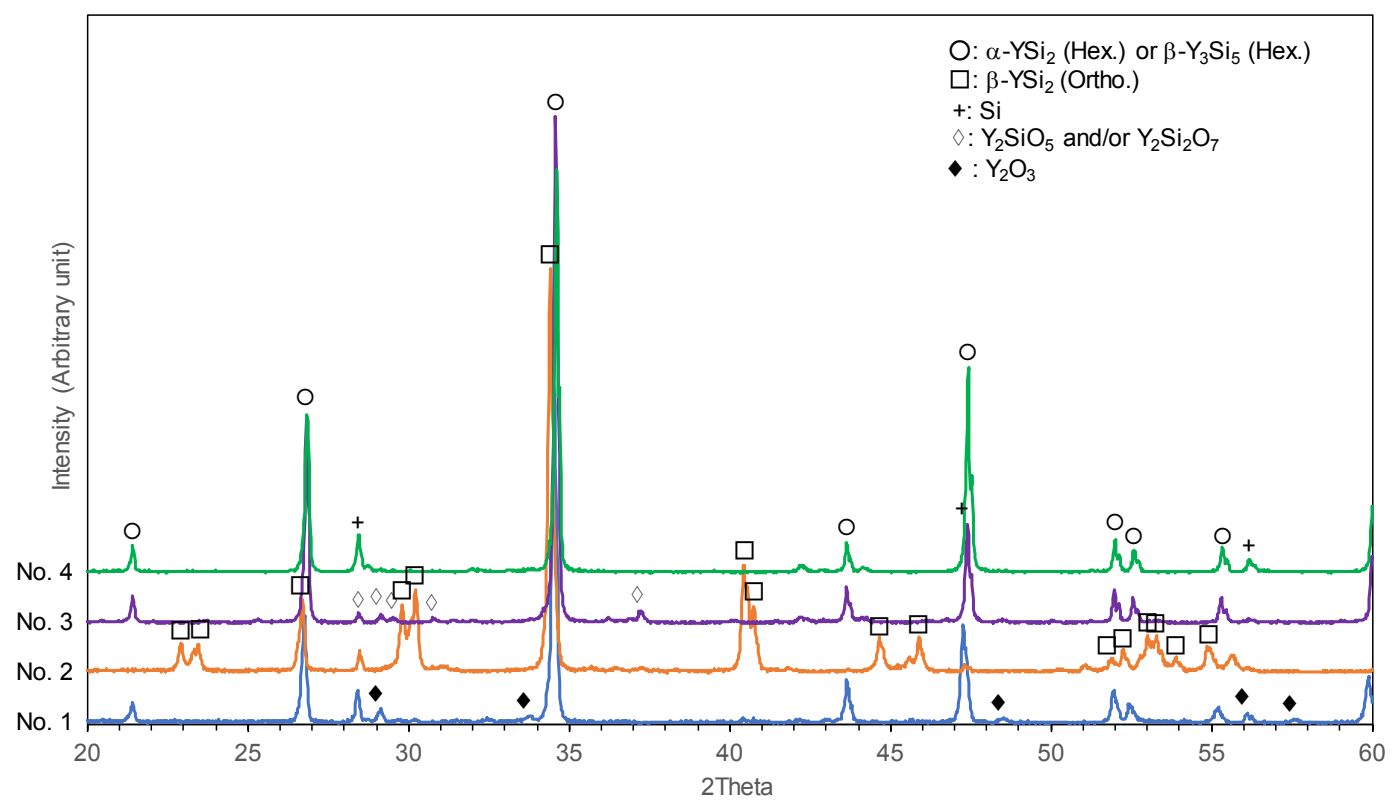

Figure 2. XRD patterns of Y-Si compounds fabricated in this work, sample No. 1-4, as shown in Table 1.

Table 1. Fabrication conditions of Y-Si compounds.

\begin{tabular}{cccccc}
\hline & \multicolumn{2}{c}{ Raw materials } & \multicolumn{3}{c}{ Heat treatment conditions } \\
\cline { 2 - 5 } No. & Yttrium & Silicon & Temp. & Duration & \multirow{2}{*}{ Atmosphere } \\
\cline { 2 - 5 } & (purity) & {$[\mathrm{O}]$} & $\left({ }^{\circ} \mathrm{C}\right)$ & $\mathrm{hr}$ & \\
\hline 1 & powder (99.9\%) & $8.3 \mathrm{~mm}(1.17 \%)$ & 1100 & 5 & Quartz tube \\
2 & powder (99.9\%) & $8.3 \mathrm{~mm}(1.17 \%)$ & 1090 & 5 & Vacuum \\
3 & powder (99.9\%) & $8.3 \mathrm{~mm}(1.17 \%)$ & 1500 & 1 & Vacuum \\
4 & ingot (99.9\%) & $-100 \mathrm{Me}(0.081 \%)$ & 1600 & 0.5 & $0.1 \mathrm{MPa} \mathrm{Ar}$ \\
5 & ingot (99.9\%) & $-100 \mathrm{Me}^{\prime}(0.081 \%)$ & 1600 & 0.5 & \multirow{2}{*}{$0.1 \mathrm{MPa} \mathrm{Ar}$} \\
\hline
\end{tabular}

Table 2. XRD identification results of Y-Si compounds prepared in this work.

\begin{tabular}{|c|c|c|c|c|c|}
\hline \multirow{2}{*}{ No. } & \multicolumn{5}{|c|}{ XRD identification results } \\
\hline & $\alpha-\mathrm{YSi}_{2}(\mathrm{Hex} .)^{\star_{1}}$ or $\beta-\mathrm{Y}_{3} \mathrm{Si}_{5}(\mathrm{Hex})$. & ${ }^{2} \beta$-YSi ${ }_{2}$ (Ortho.) ${ }^{* 1}$ & $\mathrm{Si}$ & $\mathrm{Y}_{2} \mathrm{SiO}_{5}$ and/or $\mathrm{Y}_{2} \mathrm{Si}_{2} \mathrm{O}_{7}$ & $\mathrm{Y}_{2} \mathrm{O}_{3}$ \\
\hline 1 & vs & - & $\mathrm{m}$ & $\operatorname{tr}$ & $\mathrm{w}$ \\
\hline 2 & - & vs & $\mathrm{w}$ & $\operatorname{tr}$ & - \\
\hline 3 & vs & - & $\mathrm{w}$ & $\mathrm{w}$ & - \\
\hline 4 & vs & - & $\mathrm{m}$ & - & - \\
\hline 5 & vs & - & $\mathrm{m}$ & - & - \\
\hline
\end{tabular}

Intensity: vs: very strong; w: weak; vw: very weak; tr: trace; - : not detected. ${ }^{\star} 1$ : It was reported that $\alpha$-YSi $i_{2}$ (No. 11-0596 in the PDF-ICDD) and $\beta$-YSi ${ }_{2}$ (No. 11-0324 in the PDFICDD) were the low and high temperature phases, respectively, and the phase transformation occurred at $1250^{\circ} \mathrm{C}$ [3]. ${ }^{\star} 2$ : Since it was reported that the low temperature phase $\alpha-\mathrm{Y}_{3} \mathrm{Si}_{5}$ (Ortho.) was stable below $450^{\circ} \mathrm{C}$ [9], the high temperature phase $\beta-\mathrm{Y}_{3} \mathrm{Si}_{5}$ (No. $72-2173$ in the PDF-ICDD) would be the stable phase in the current experimental condition. It was also reported that $\alpha$-YSi $i_{2}$ and $\beta-\mathrm{Y}_{3} \mathrm{Si}_{5}$ had the identical crystal structure, $\mathrm{P} 6 / \mathrm{mmm}$, and $\beta-\mathrm{Y}_{3} \mathrm{Si}_{5}$ had defect structure: $\mathrm{Si}$ atoms occupy $83 \%$ of the $2(\mathrm{~d})$ positions in the space group $\mathrm{P} 6 / \mathrm{mmm}$ [13]. 
Table 3. Comparison of powder XRD peak data obtained in this work with Powder Diffraction File (PDF) database registered by $\operatorname{ICDD}^{\star}(1)$ Hexagonal crystal structure.

\begin{tabular}{|c|c|c|c|c|c|c|}
\hline \multicolumn{4}{|c|}{ PDF database } & \multirow{2}{*}{\multicolumn{3}{|c|}{$\begin{array}{l}\text { Sample No. and their powder XRD } \\
\text { peak data obtained in this work }\end{array}$}} \\
\hline Card No. & Compound & Card No. & Compound & & & \\
\hline 11-0596 & $\mathrm{YSi}_{2}$ & $72-2173$ & $\mathrm{Y}_{3} \mathrm{Si}_{5}$ & No. 1 & No. 3 & No. 4 \\
\hline$h k l$ & $2 \theta$ & $h k l$ & $2 \theta$ & $2 \theta$ & $2 \theta$ & $2 \theta$ \\
\hline 001 & 21.446 & 001 & 21.446 & 21.42 & 21.42 & 21.40 \\
\hline 100 & 26.831 & 100 & 26.772 & 26.76 & 26.82 & 26.84 \\
\hline 101 & 34.604 & 101 & 34.557 & 34.54 & 34.58 & 34.62 \\
\hline 002 & 43.692 & 002 & 43.694 & 43.64 & 43.64 & 43.64 \\
\hline 110 & 47.331 & 110 & 47.280 & 47.26 & 47.40 & 47.42 \\
\hline 102 & 52.068 & 102 & 51.986 & 51.96 & 51.98 & 52.00 \\
\hline 111 & 52.551 & 111 & 52.470 & 52.42 & 52.56 & 52.58 \\
\hline 200 & 55.258 & 200 & 55.165 & 55.22 & 55.30 & 55.34 \\
\hline 201 & 59.938 & 201 & 59.869 & 59.90 & 59.98 & $60<$ \\
\hline
\end{tabular}

Table 4. Comparison of powder XRD peak data obtained in this work with Powder Diffraction File (PDF) database registered by $\operatorname{ICDD}^{\star}(2)$ Orthorhombic crystal structure.

\begin{tabular}{|c|c|c|}
\hline \multicolumn{2}{|c|}{ PDF database } & \multirow{3}{*}{$\begin{array}{c}\text { Powder XRD peak data } \\
\text { of sample No. } 2\end{array}$} \\
\hline Card No. & Compound & \\
\hline $11-0324$ & $\mathrm{YSi}_{2}$ & \\
\hline$h k l$ & $2 \theta$ & $2 \theta$ \\
\hline 101 & 22.961 & 22.92 \\
\hline 011 & 23.452 & 23.46 \\
\hline 004 & 26.748 & 26.70 \\
\hline 103 & 29.856 & 29.80 \\
\hline 013 & 30.271 & 30.22 \\
\hline 112 & 34.465 & 34.40 \\
\hline 105 & 40.413 & 40.44 \\
\hline 015 & 40.795 & 40.74 \\
\hline 200 & 44.69 & 44.64 \\
\hline 020 & 45.86 & 45.90 \\
\hline 116 & 52.194 & 52.24 \\
\hline 204 & 52.942 & 53.00 \\
\hline 107 & 53.208 & 53.28 \\
\hline 017 & 53.409 & 53.44 \\
\hline 024 & 53.781 & 53.90 \\
\hline 213 & 54.933 & 54.96 \\
\hline
\end{tabular}


When high purity metal powders were used, only diffraction peaks attributed to the hexagonal phase and Si are observed for sample No. 4 and almost no other oxide phases exist. A fact that the stoichiometric mixture of $\mathrm{Y}: \mathrm{Si}=1: 2$ resulted in the formation of Si suggests that the hexagonal phase would not be $\alpha-\mathrm{YSi}_{2}$ but $\beta-\mathrm{Y}_{3} \mathrm{Si}_{5}$, which would be further supported by the fact that the sample No. 4 was heat-treated at as high as $1600^{\circ} \mathrm{C}$, at which this mixture should form a homogeneous liquid phase according to the $\mathrm{Y}$-Si phase diagram [1]. To confirm whether the mixture of $\beta-Y_{3} \mathrm{Si}_{5}$ and $\mathrm{Si}$ would be the stable phases for the stoichiometric mixture of $\mathrm{Y}: \mathrm{Si}=1: 2$, sample No.4 was further heat-treated at $1100^{\circ} \mathrm{C}$ for $12 \mathrm{hrs}$, which was specified as sample No. 5 in Table 1 . This equilibration process did not change the diffraction peaks observed for sample No. 4 at all, supporting the hypothesis above mentioned. A recent study regarding the fabrication of $\mathrm{YSi}_{2}$ by the spark plasma sintering at $1273 \mathrm{~K}$ under Ar atmosphere using high purity metals also demonstrated that the main peaks of all samples agreed well with the $\mathrm{YSi}_{1.67}$ standard pattern (JCPDS 01-071-3919), representing the single phase of the $\mathrm{AlB}_{2}$-type structure $(\mathrm{P} 6 / \mathrm{mmm})$ [12]. It would be interesting that the $2 \theta$ values of all diffraction peaks of the $\beta-\mathrm{Y}_{3} \mathrm{Si}_{5}$ hexagonal lattice shifted in the order of sample No. $1>$ No. $3>$ No. 4 as shown in Table 3, suggesting that their lattice constants would be enlarged with the amount of oxygen impurity.

As described in the introduction, although the latest $\mathrm{Y}$-Si phase diagram shown in Figure 1 [1] demonstrated that the $\alpha$ - and $\beta$-YSii 2 phases were the stable phases for the stoichiometric composition of $\mathrm{Y}: \mathrm{Si}=1: 2$ adopting the experimental results clearly showing their existences [6] [7]. However, a detailed investigation of phase equilibria and crystal structures of the compounds taking the effects of impurity oxygen into account demonstrated that the formation of $\mathrm{YSi}_{2}$ was not confirmed as a stable phase [4]. As a result, there have been several phase diagrams for the $\mathrm{Y}-\mathrm{Si}$ system. The current experimental results suggest that the high temperature phase with the hexagonal structure, $\beta-\mathrm{Y}_{3} \mathrm{Si}_{5}$, would be the stable phase even for the stoichiometric composition of $\mathrm{Y}: \mathrm{Si}=1: 2$, and that the high temperature phase with the orthorhombic structure, $\beta$-YSi ${ }_{2}$, would be the meta-stable phase under high oxygen impurity content. Further investigation would be necessary to clarify the phase diagram of Y-Si system.

\subsection{Chemical Stabilities of Y-Si Compounds}

Figure 3 and Figure 4 show the appearances of $\alpha$ type and $\beta$ type $\mathrm{YSi}_{2}$ powders (sample No. 2 and 3), respectively, immersed in purified water, methanol, ethanol, propanol, butanol, benzene, $n$-hexane, or acetonitrile (from the left end to the right end) settled for $0,1,2,4,8,16$ and $24 \mathrm{hrs}$ at room temperature under the atmospheric condition. It was observed that the dispersibility increased in the order as follows, water $<$ methanol $<$ ethanol $<2$-propanol $>$ butanol $\sim$ acetonitrile $>>$ benzene $\sim n$-hexane, demonstrating that the best solvent is propanol for dispersing $\mathrm{YSi}_{2}$ powders. There was almost no difference between $\alpha$ type and $\beta$ type $\mathrm{YSi}_{2}$ powders, but $\beta$ type showed better dispersibility after long duration, which would be due to the difference of mean particle sizes of both powders, 17 
$\mu \mathrm{m}$ and $10 \mu \mathrm{m}$, respectively. It should be noted that neither the formation of bubbles nor white precipitates was observed in all solvents even after $24 \mathrm{hrs}$ for both powders, suggesting much superior chemical stability to solvents of $\mathrm{YSi}_{2}$ powders than Yttrium metal and Alkaline Earth Silicides, for which the formation of bubbles and/or white precipitates were observed in all solvents immediately after dispersing these powders.

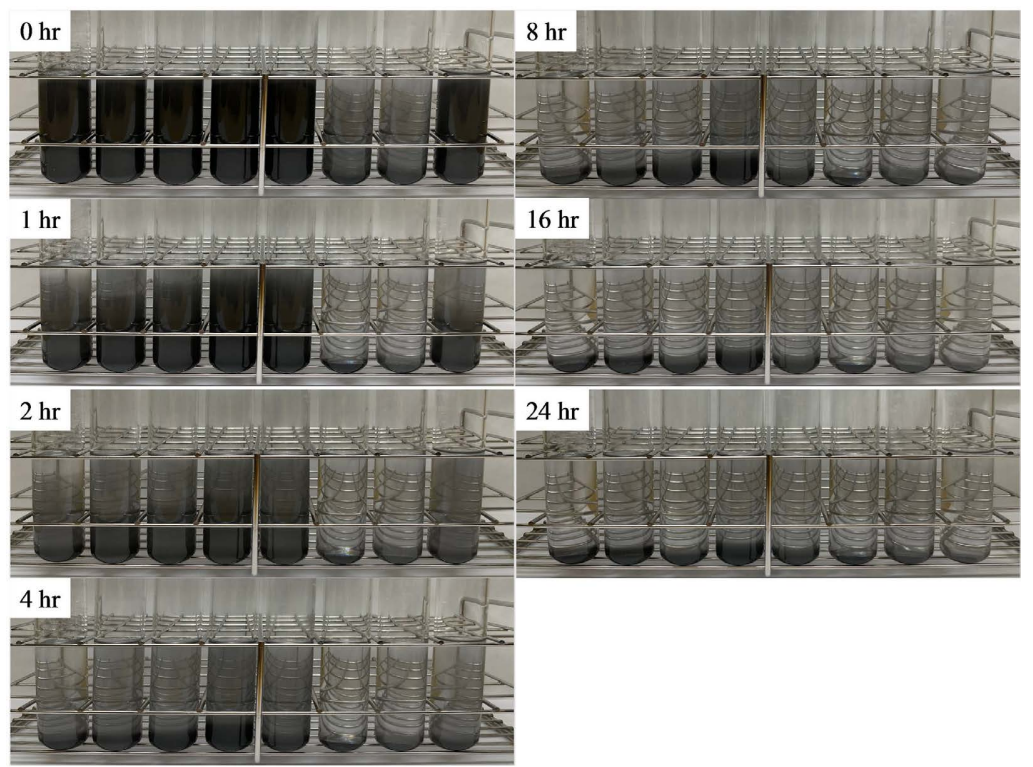

Figure 3. Appearances of $\alpha$ type powders (sample No. 2) immersed in purified water, methanol, ethanol, propanol, butanol, benzene, $n$-hexane, or acetonitrile (from the left end to the right end) settled for 0, 1, 2, 4, 8, 16 and $24 \mathrm{hrs}$ at room temperature under the atmospheric condition.

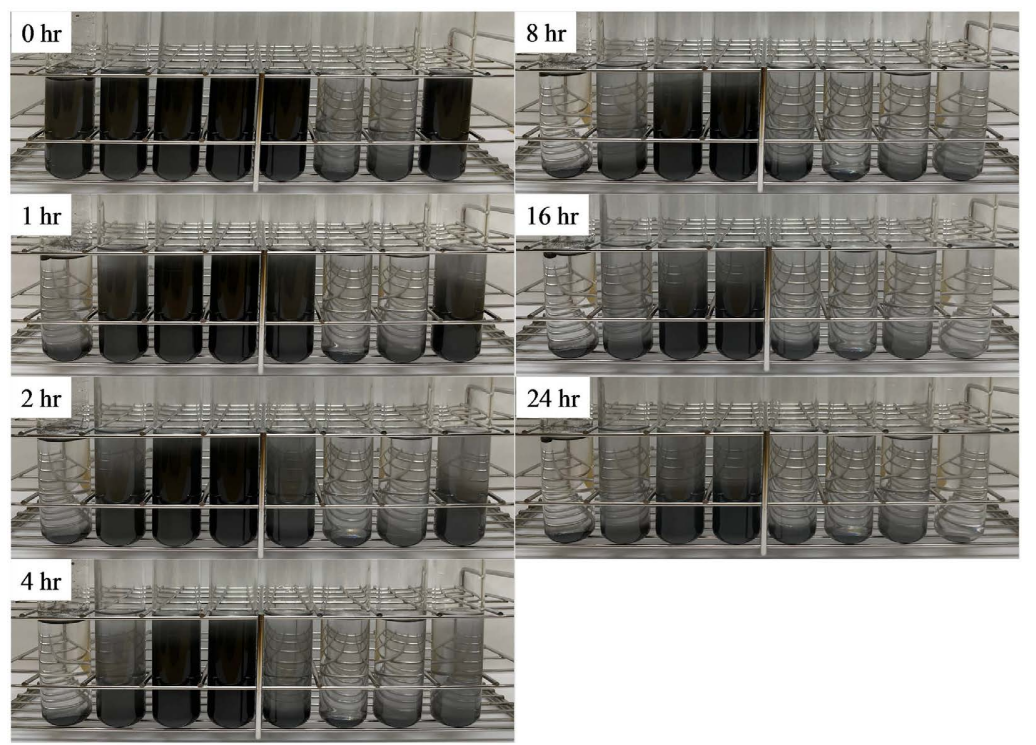

Figure 4. Appearances of $\beta$ type powders (sample No. 3) immersed in purified water, methanol, ethanol, propanol, butanol, benzene, $n$-hexane, or acetonitrile (from the left end to the right end) settled for $0,1,2,4,8,16$ and $24 \mathrm{hrs}$ at room temperature under the atmospheric condition. 
Table 5. Oxygen contents of $\mathrm{YSi}_{2}$ powders with low and high purity before and after grinding.

\begin{tabular}{ccccc}
\hline \multirow{2}{*}{$\begin{array}{c}\text { Powder } \\
\text { sample }\end{array}$} & \multicolumn{4}{c}{ Oxygen content (wt\%) } \\
\cline { 2 - 5 } & Before grinding & \multicolumn{3}{c}{ After grinding in } \\
\cline { 2 - 5 } & $<150 \mu \mathrm{m}$ & 2-propanol & $n$-hexane & acetonitrile \\
\hline $\begin{array}{c}\text { No. 3 } \\
\text { (low purity) }\end{array}$ & 1.40 & 2.51 & 2.53 & 2.6 \\
$\begin{array}{c}\text { No. } 4 \\
\text { (high purity) }\end{array}$ & 0.59 & 1.70 & 1.39 & 1.77 \\
\hline
\end{tabular}

Table 5 summarizes the oxygen contents of $\mathrm{YSi}_{2}$ powders with low and high purity, sample No. 3 and 4 respectively, before and after grinding in 2-propanol, $n$-hexane or acetonitrile at room temperature under the atmospheric condition. It was confirmed that the use of high purity metals resulted in reducing oxygen content by about $58 \%$ comparing to the low purity metal powders. After grinding these powders in a ball mill at $120 \mathrm{rpm}$ for $12 \mathrm{hrs}$ using 2-propanol, $n$-hexane, or acetonitrile as solvents, the oxygen contents increased significantly probably due to the mechano-chemical effect. Although those solvents without hydroxy group, $n$-hexane and acetonitrile, were expected not to increase the oxygen content, there was almost no difference for oxygen contents after milling in all solvents for powder sample No. 3 (low purity). However, for powder sample No. 4 (high purity), $n$-hexane gave the least oxygen content probably due to its less contents of oxides such as $\mathrm{Y}_{2} \mathrm{SiO}_{5}$ and/or $\mathrm{Y}_{2} \mathrm{Si}_{2} \mathrm{O}_{7}$ as shown in Table 2.

\section{Conclusion}

Y-Si compounds with the composition of $\mathrm{Y}: \mathrm{Si}=1: 2$ were fabricated using Yttrium and Silicon raw powders with low and high purity in various atmospheres and temperatures. Although the latest Y-Si phase diagram demonstrated that the $\alpha$ - and $\beta$-YSi $i_{2}$ phases were the stable phases for the stoichiometric composition of $\mathrm{Y}: \mathrm{Si}=1: 2$, the current experimental results suggest that the high temperature phase with the hexagonal structure, $\beta-Y_{3} \mathrm{Si}_{5}$, would be the stable phase even for the stoichiometric composition of $\mathrm{Y}: \mathrm{Si}=1: 2$, and that the high temperature phase with the orthorhombic structure, $\beta$-YSi ${ }_{2}$, would be the meta-stable phase under high oxygen impurity content. It was demonstrated that $\mathrm{YSi}_{2}$ powders possess much superior chemical stability than Yttrium metal. It was found that the best dispersing solvent for $\mathrm{YSi}_{2}$ powder was 2-propanol.

\section{Conflicts of Interest}

The authors declare no conflicts of interest regarding the publication of this paper.

\section{References}

[1] Okamoto, H. (2011) Si-Y (Silicon-Yttrium). Journal of Phase Equilibria and Diffu- 
sion, 32, 475-476. https://doi.org/10.1007/s11669-011-9936-4

[2] Shukla, A., Kang, Y.B. and Pelton, A.D. (2009) Thermodynamic Assessment of the $\mathrm{Ce}-\mathrm{Si}, \mathrm{Y}-\mathrm{Si}, \mathrm{Mg}-\mathrm{Ce}-\mathrm{Si}$, and Mg-Y-Si Systems. International Journal of Materials Research, 100, 208-217. https://doi.org/10.3139/146.110003

[3] Gokhale, A.B. and Abbaschian, G.L. (1986) The Si-Y (Silicon-Yttrium) System. Bulletin of Alloy Phase Diagrams, 7, 485-489. https://doi.org/10.1007/BF02867814

[4] Button, T.W., McColm, I.J. and Ward, J.M. (1990) Preparation of Yttrium Silicides and Oxide-Silicides. Journal of the Less Common Metals, 159, 205-222. https://doi.org/10.1016/0022-5088(90)90149-E

[5] Okamoto, H. (1991) Si-Y (Silicon-Yttrium). Journal of Phase Equilibria, 12, 397-399. https://doi.org/10.1007/BF02649941

[6] Polotshkaya, R.I. and Sidorko, V.R. (1997) Thermodynamic Properties of Yttrium Silicides. Powder Metallurgy and Metal Ceramics, 36, 315-319. https://doi.org/10.1007/BF02676225

[7] Meschel, S.V. and Kleppa, O.J. (1998) Standard Enthalpies of Formation of Some 4d Transition Metal Silicides by High Temperature Direct Synthesis Calorimetry. Journal of Alloys and Compounds, 274, 193-200. https://doi.org/10.1016/S0925-8388(98)00504-0

[8] Perri, J.A., Binder, I. and Post, B. (1959) Rare Earth Metal “Disilicides”. The Journal of Physical Chemistry, 63, 616-619. https://doi.org/10.1021/j150574a041

[9] Perri, J.A., Banks, E. and Post, B. (1959) Polymorphism of Rare Earth Disilicides. The Journal of Physical Chemistry, 63, 2073-2074. https://doi.org/10.1021/j150582a030

[10] Mayer, I.P., Banks, E. and Post, B. (1962) Rare Earth Disilicides. The Journal of Physical Chemistry, 66, 693-696. https://doi.org/10.1021/j100810a028

[11] Williams, J. and Akinc, M. (1997) Processing and Oxidation Behavior of $\mathrm{Y}_{5} \mathrm{Si}_{3}$. Ceramic Engineering and Science Proceedings, 18, 571-578. https://doi.org/10.1002/9780470294437.ch62

[12] Wongprakarn, S., Pinitsoontorn, S., Tanusilp, S. and Kurosaki, K. (2018) Thermoelectric Properties of Bulk Yttrium Silicide $\left(\mathrm{YSi}_{2}\right)$ Fabricated by Arc Melting and Spark Plasma Sintering. Physica Status Solidi $(A), 215,1700769$. https://doi.org/10.1002/pssa.201700769

[13] Gladyshevskii, E.I. and Émes-Misenko, E.I. (1964) Crystal Strucrtures of Silicon-Rich Scandium and Yttrium Silicides. Journal of Structural Chemistry, 4, 793-795. https://doi.org/10.1007/BF00747715 